$7 \quad$ aaculty of Human Sciences, Sophia University, 7-1 Kioi-cho, Chiyoda-ku, Tokyo, 102-

8 8554, Japan.

9 braduate School of Arts and Sciences, The University of Tokyo, 3-8-1 Komaba,

10 Meguro-ku, Tokyo 153-8902, Japan.

$11{ }^{\mathrm{c}}$ Institute for Education and Human Development, Ochanomizu University, 2-1-1

12 Otsuka, Bunkyo-ku, Tokyo 112-8610, Japan. 


\section{$20 \quad$ Abstract}

21 Space-valence metaphors (e.g., bad is down) are embedded within cognitive and

22 emotional processing (e.g., negative stimuli at a lower space capture visual attention

23 more than those at an upper space). Previous studies have revealed that motor action to

24 vertical direction affects the emotional valence rating of stimuli in a metaphor-

25 congruent manner only when the action was introduced after the stimuli presentation. In

26 the present study, we hypothesized that motor action before the stimuli presentation

27 does not affect valence rating while it may affect visual selective attention. In

28 Experiment 1 (participants: 28 university students; mean age $=19.50$ years), we

29 partially replicated the previous result with repeated ANOVA and $t$-tests; manual action

30 introduced before the stimuli presentation does not affect the valence rating. Then, in

31 Experiment 2 (participants: 28 university students; mean age $=19.57$ years), we

32 employed a modified version of the dot-probe task as a measure of visual selective

33 attention to emotional stimuli, where participants' vertical or horizontal manual action

34 was introduced before the presentation of a pair of emotional words. The results of the $t$ -

35 tests revealed that an upward manual action promoting selective attention to negative

36 words, which was incongruent with the space-valence metaphorical correspondence.

$37 \quad$ These results suggest that even though manual action does not affect the evaluative

38 process of emotional stimuli prospectively, upward manual action introduced before

39 stimuli presentation can promote visual attention to the subsequent negative stimuli in a

40 way that is incongruent with the space-valence metaphor. 


\section{Introduction}

When we express our emotional experiences in daily life, we use spatial

44 metaphors naturally. For example, when we want someone to feel better, we may say,

$45 \quad$ "Cheer up." Such space-valence metaphors do not merely appear in the form of slang or

46 idioms; they exist in human cognition and emotions. In the early work of Wapner,

47 Werner, and Krus (1957), participants bisected a luminous square with a black line

48 before and after a midterm test. The results showed that the participants who succeeded

49 in the midterm test tended to shift the bisecting line upward after the test, whereas those

50 who failed shifted the line downward. In recent decades, such "metaphor-congruent"

51 effects, which promote cognitive processes such as memory in a manner that is

52 congruent with space-valence metaphors, have been continuously reported (Crawford \&

53 Cacioppo, 2002; Crawford, Margolies, Drake, \& Murphy, 2006; see also Lynott \&

54 Coventry, 2014). What is the mechanism underlying these effects of space-valence

$55 \quad$ metaphors? 
57 structure and define; thus, people use metaphors for more concrete and simple concepts

58 that can be understood through daily experiences to help describe abstract concepts. For

59 example, concepts like "prosperity" and "decline" are abstract and vague; thus, it may

60 be difficult to understand them intuitively. As a result, we try to understand them by

61 using metaphors like spatial metaphors (for example "prosperity is up, decline is

62 down”), although such abstract concepts often require combinations of multiple

63 metaphors to be understood thoroughly. Similarly, it could be assumed that people also

64 use spatial metaphors to understand internal and external emotional signals, which are

65 often vague and invisible.

66

Recently, researchers have demonstrated that emotions can affect visual

67 attention in a metaphor-congruent manner. Meier and Robinson (2004) revealed that

68 positive (or negative) evaluation of stimuli promoted information processing in the

69 upper (or lower) area of the screen. This result suggests that the emotional valence of

70 stimuli can affect spatial attention in a metaphor-congruent manner. Moreover, Meier

71 and Robinson (2006) reported that stronger selective attention was allocated when 
72 neutral stimuli appeared in the lower half of the screen among participants with higher

73 neuroticism, suggesting a "bad is down" metaphor on selective attention to visual

74 stimuli, while there was no significant effect for "good is up". Additionally, Zhang, Li,

75 and Zuo (2014) reported that their participants felt happy when they gazed at the top of

76 the screen and depressed when they gazed at the bottom, which shows that attention

77 affects emotion in metaphor-congruent manner.

Another line of research reported evidence of interactions between body

79 movement and emotion; for example, interactions between proprioception and emotion

80 (e.g., Oosterwijk, Rotteveel, Fischer, \& Hess, 2009; Riskind \& Gotay, 1982) and

81 cutaneous sensation and emotional cognition (e.g., Fetterman, Wilkowski, \& Robinson,

82 2018). Some previous studies have observed the effect of motor action on emotional

83 cognition (Förster \& Strack, 1997, 1998; Maxwell \& Davidson, 2007). Cognition that

84 interacts with somatosensory and motor signals is called embodied cognition; more

85 recently, studies have reported that vertical action corresponding to space-valence

86 metaphors can modulate cognitive processing. Casasanto and Dijkstra (2010) reported 
87 that participants recalled their memories faster when movement and memory valence

88 were metaphor-congruent, as upward movement promoted the recollection of positive

89 memories while downward movement promoted the recollection of negative memories.

90 Additionally, the findings presented by Sasaki, Yamada, and Miura (2015) may serve as

91 a supplement to those of Casasanto and Dijkstra (2010). In the study by Sasaki et al.

92 (2015), emotional visual stimuli were presented on a touch screen, and subsequently, the

93 participants manually moved a cursor upward, downward, or horizontally on the screen.

94 When participants rated the emotional valence of the stimuli immediately after the

95 upward (or downward) movement, the stimuli were found to be more positively (or

96 negatively) rated. It seems reasonable that metaphor-congruent emotional processing is

97 caused by vertical manual action, as suggested by evidence from embodied cognition.

Our previous study (Kato, Imaizumi, \& Tanno, 2018) replicated Sasaki et al.

99 (2015) and included a condition where vertical manual action was introduced before the

100 stimuli presentation. Subsequently, Kato et al. (2018) revealed that the valence rating

101 was affected by the vertical manual action only retrospectively, not prospectively. Both 
102 Kato et al. (2018) and Sasaki et al. (2015), however, only examined the effect of

103 metaphor-inductive action on valence rating. This absence of prospective effect can be

104 specific to the valence-rating task. As previous studies including Casasanto and Dijkstra

105 (2010) have paid attention to relatively higher-order cognition (memory or affective

106 ratings), we should also explore lower-order cognitive features such as attention or

107 perception to find prospective effects of manual action on emotional processing. The

108 evidence of an interaction between action and attention has been studied for a long time

109 (e.g., Gherri \& Eimer, 2010; as a review, Smith \& Schenk, 2012), and it is believed that

110 metaphor-inductive action may affect visual attention. Thus, in the present study, we

111 investigated the effect of metaphor-inductive action on attention to emotional stimuli.

112 In the present study, we introduced manual action before presenting emotional

113 stimuli in order to investigate the effect of metaphor-inductive action. As introduced,

114 spatial metaphor affects autobiographical memory or visual attention, thus we should

115 expect a prospective effect of metaphor-inductive action on these cognitive aspects.

116 According to these previous findings, the present study aimed at investigating the 
117 prospective effect of metaphor-inductive action on visual attention.

118 Though there is no previous report on the relationship between metaphor-

119 inductive action and spatial attention, it is possible to expect similar results as shown in

120 previous studies. For example, previous studies have observed that stimuli were

121 processed faster when they were placed in a position congruent with a space-valence

122 metaphor (e.g., Meier, Hauser, Robinson, Friesen, \& Schjeldahl, 2007; Meier \&

123 Robinson, 2006). If metaphor-congruent effects promote the processing of emotional

124 stimuli, detection of emotional stimuli may also be promoted (or may become the cause

125 of faster reaction time [RT]) by vertical manual action. Thus, this study aimed to

126 investigate the effects of vertical manual action on subsequent attention to negatively or

127 positively valenced visual stimuli. The present study introduced manual action into a

128 dot-probe task, which is an established task used to measure selective visual attention to

129 emotional stimuli (MacLeod, Mathews, \& Tata, 1986). Emotional words were

130 presented after a manual action, and attentional bias (if any) towards the emotional

131 verbal stimuli (words with emotional valence) was measured. At the same time, we 
132 attempted to replicate the result of Kato et al. (2018) to confirm that vertical manual

133 action did not prospectively affect the valence rating of emotional stimuli at first, as

$134 \quad$ Kato et al. (2018) used pictorial stimuli while the present study used emotional words

135 as emotional verbal stimuli. Thus, in Experiment 1, we tested if vertical manual action

136 affected the perceived valence of emotional stimuli in the present experiment setting. In

137 Experiment 2, we employed a modified version of the dot-probe task and examined the

138 effects of vertical manual action on the selective visual attention to the emotional

139 stimuli used in Experiment 1. It can be expected that the manual action would not affect

140 the valence rating of the subsequently presented emotional stimuli (Kato et al., 2018) in

141 Experiment 1; however, attention would be affected by the orientation of manual action

142 in metaphor-congruent ways, whereby upward movements promote attention to

143 positive stimuli, and downward movements promote attention to negative stimuli,

144 analogous to the findings of Casasanto and Dijkstra (2010) and Sasaki et al. (2015).

145 Nevertheless, given the findings of Meier and Robinson (2006), we could expect the

146 "bad is down" pattern to appear in attentional biases to emotional stimuli in Experiment 
$147 \quad 2$.

148

149 2. Experiment 1

$150 \quad$ 2. 1 . Methods

151 2. 1. 1. Participants. A total of 28 university students (mean age $=19.50, S D=$

$152 \quad 0.84 ; 14$ females) from introductory psychology classes at the University of Tokyo

153 participated in this study. The sample size was based on a priori power analysis with

$154 \quad G^{*}$ Power 3.1.9.3 (Faul, Erdfedler, Buchner, \& Lang, 2009). We assumed the large effect

155 size ( $d=.80$, according to the previous study; Kato et al., 2018) of a two-tailed one-

156 sample $t$-test (alpha $=.05$, beta $=.05)$, and found that a sample size above 23 was

157 required for the present experimental design. Before the task began, participants

158 answered the Japanese version (Okubo, Suzuki, \& Nicholls, 2014) of the Flinders

159 Handedness Survey questions (Nicholls, Thomas, Loetscher, \& Grimshaw, 2013), which

160 includes 10 items on hand usage in daily situations (scores ranged from -10 [left-

161 handed] to 10 [right-handed]). As a result, all of the participants were right-handed 
162 except for one who was mixed-handed $(M=9.50, S D=1.20)$. In the present study, we

163 were interested in evaluating the spatial metaphor for upward and downward movement.

164 The previous study by Casasanto (2009) showed that a spatial metaphor for vertical

165 spatial direction (up/down) was not influenced by handedness. Moreover, the data

166 showed that there was no difference between the left and right conditions in the present

167 study (see 2.1.5 Analyses). Thus, the data of the mixed-handed participant were

168 included in the present analyses. The participants also completed the Japanese version

169 (Shima, Shikano, Kitamura, \& Asai, 1985) of the Center for Epidemiological Studies

170 Depression scale (CES-D; Radloff, 1977) because depression can affect judgment of

171 emotional stimuli (Kohler, Hoffman, Eastman, Healey, \& Moberg, 2011). The CES-D is

172 a self-report questionnaire that includes 20 items rated on a 4-point Likert scale,

173 measuring the feelings of the participants during the past week (score range: 0 to 60).

174 The CES-D score $(M=12.93, S D=8.41)$ was comparable to the previous study on

175 healthy Japanese community dwellers $(M=14.11, S D=10.13 ; N=1181$; Takano, Mori,

176 Nishiguchi, Moriya, \& Raes, 2017) as the difference between these samples was small 
$177 \quad$ (Cohen's $d=0.13)$.

178 Each participant provided written informed consent before the experiment. The

179 present study was conducted in accordance with the Declaration of Helsinki and was

180 approved by the local ethical committee of the Graduate School of Arts and Sciences at

181 the University of Tokyo (approval number 468).

182

183 2. 1. 2. Materials. We selected 16 words each from the neutral, negative, and

184 positive categories to use as emotional stimuli (see Appendix). Negative and neutral

185 words were selected from familiarity-controlled word-sets collected from our previous

186 study (Nishiguchi, Takano, \& Tanno, 2015), originally from the word list of Matsumoto

187 (2006). Positive words were selected from Matsumoto (2006), and their familiarity was

188 matched to that negative and neutral words. An additional two neutral words were used

189 in the practice trials. 
192 laboratory. The experimental setup was mostly identical to the one used in Kato et al.

193 (2018). Participants performed a rating task, sitting approximately $57 \mathrm{~cm}$ from a 24-inch 194 liquid-crystal monitor with a refresh rate of $60 \mathrm{~Hz}$ (V242, Hewlett Packard, Palo Alto, 195 USA) on the table. Their head positions were fixed using a chinrest. A joystick (Cyborg 196 V.1 Flight Stick; Mad Catz, San Diego, USA) was positioned on a board erected 197 perpendicularly to the table, as the bottom of the joystick was grounded on the board on 198 the right side of the participant. Due to this setting, the direction of joystick 199 manipulation and cursor movement are matched in the task explained in the following 200 section. On the left side of the participant was a keyboard that was placed on a table; 201 thus, each participant manipulated the joystick with their right hand and the numeric 202 keypad with their left hand. Stimulus presentation and response collection were 203 controlled by E-Prime 2.0 (Psychology Software Tools, Pittsburgh, USA) on a Windows $204 \quad 10$ computer. 
207 Experiment 1 in Kato et al. (2018), without a retrospective condition. According to the

208 orientation of the joystick manipulation, there were vertical and horizontal sessions. In

209 the vertical session, the trial was started with the first fixation phase. A fixation cross

210 (approximately $1.0^{\circ}$ in width, $1.0^{\circ}$ in height) appeared at the center of the screen for

$211 \quad 1,000 \mathrm{~ms}$, followed by the action phase. In the action phase, the fixation cross did not

212 disappear, and red and blue bars (action cues, both approximately $51.8^{\circ}$ in width, $8.1^{\circ}$ in

213 height) appeared at the top and bottom of the screen; at the same time, a cursor (a white

214 cross, approximately $0.6^{\circ} \times 0.6^{\circ}$ ), which could be manipulated with the joystick,

215 appeared at the center of the screen. There was space between the bars at the top and

216 bottom of the screen $\left(51.8^{\circ}\right.$ in width, $14.5^{\circ}$ in height). In half of the trials, a red bar

217 appeared at the top of the screen, and in the other half, it appeared at the bottom of the

218 screen. The colors of the bars, red and blue, were chosen to make the similar experiment

219 setting as the previous studies (Kato et al., 2018; Sasaki et al., 2015). When the red and

220 blue bars appeared, the participants were required to move the cursor to the red or blue

221 bar within 1,000 ms. The destination of the cursor (the red or blue bar) was fixed for 
222 participants throughout the experiment, but was counterbalanced across the participants.

223 In this manner, the participants moved the cursor in the upward direction for half of the

224 trials and in the downward direction for the other half. If participants moved the cursor

225 to the wrong bar or if the $1,000 \mathrm{~ms}$ mark was crossed, the trial was counted as an error

226 and excluded from the analysis. After the participants either moved their cursors to the

227 bar or when 1,000 ms elapsed, the bars and cursors were replaced by a 1,000 ms

228 presentation of the second fixation phase. During this period, participants were required

229 to return the joystick to the default (central) position to avoid any interference of the

230 vision and movement of their arm on the subsequent stimulus presentation. Notably,

231 action and its sensory outcome can be temporally bound to one another, even with

232 temporal intervals longer than 1,000 ms (Humphreys \& Buehner, 2009). Next, the cue

233 presentation phase started with one of the emotional words (approximately $2.0^{\circ} \times 1.0^{\circ}$ )

234 appearing at the center of the screen for $1,000 \mathrm{~ms}$. Then, the participants rated the

235 emotional valence of the word on a 7-point Likert scale ranging from -3 (strongly

236 negative) to 3 (strongly positive) by pressing a numeric key horizontally aligned on the 
237 keyboard (1 to 7 keys; i.e., the 1 key for " -3 " and the 7 for " 3 ") with no time pressure.

238 This took place in one experimental block. There were eight trials each for all

239 combinations of action orientations (upward and downward) and stimulus valences

240 (negative, neutral, and positive), resulting in 48 trials. There was also the horizontal

241 session, in which only the locations of the action cues were different from those in the

242 trials of the vertical session. The red and blue bars appeared to the left and right of the

243 central fixation. Both bars were approximately $18.7^{\circ}$ in width and $32.4^{\circ}$ in height,

244 matching the width of the space between the two bars (i.e., they required an amount of

245 arm displacement), and were approximately the same as the vertical session $\left(14.5^{\circ}\right)$. The

246 number of trials and block design was the same as in the vertical session. The order of

247 the sessions was counterbalanced across participants.

In the present task, the joystick manipulation before the stimuli presentation

249 required both arm flexion and contraction because participants had to move the cursor

250 by manipulating the joystick, and then move it back to the default position. Some

251 previous studies had tasks which required both arm flexion and contraction in one trial 
252 and successfully found a metaphor-congruent effect (Casasanto \& Dijkstra, 2010; Kato

253 et al., 2018). Thus, we believe that this requirement did not alter the results.

256 participant and confirmed that there was no significant difference in the rating scores

257 between the left and right conditions ( $p$-values are Bonferroni-corrected for three $t$-tests;

258 negative stimuli, $t(27)=0.07, p=1.000, d=0.02$; neutral stimuli, $t(27)=-1.02, p=.946$,

$259 d=0.17$; positive stimuli, $t(27)=-0.83, p=1.000, d=0.14)$ thus, we averaged the scores

260 of left and right conditions and treated them as a horizontal condition. A two-way repeated

261 measure (stimuli valence and orientation) ANOVA was conducted on the valence ratings. caused by upward and downward joystick manipulation, compared to the horizontal condition. The changes in valence ratings were calculated by subtracting the average rating score in the horizontal condition from that in the upward and downward conditions

266 for negative, positive, and neutral words. Then, for the main purpose of Experiment 1, we 
267 conducted $t$-tests to examine whether upward and downward manual action changed

268 valence rating, following the analyses procedure of Kato et al. (2018). Finally, a

269 correlation analysis was conducted to examine the effect of depressive symptoms on the

$270 \quad$ change of valence ratings.

$271 \quad$ 2. 2. Results

272

We conducted a two-way repeated measure ANOVA on the valence ratings,

273 with stimuli valence (negative, positive, neutral) and orientation (upward, downward,

274 horizontal) as within-participants factor. There was a significant main effect of valence

$275 \quad\left(F(2,54)=1022.66, p<.001, \eta_{p}^{2}=.974\right)$ without interaction from orientation

$276 \quad\left(\right.$ Greenhouse-Geisser corrected $\left.F(1.30,35.19)=0.25, p=.683, \eta_{p}^{2}=.009\right)$. There was

277 no main effect of orientation (Greenhouse-Geisser corrected $F(2.66,71.78)=2.63, p$

$\left.278=.063, \eta_{p}^{2}=.089\right)$

279 Then, for the primary purpose of the present experiment, we calculated the

280 changes in valence rating in the upward and downward conditions for negative,

281 positive, and neutral words (Figure 2). We examined the difference between the changes 
282 in valence ratings and zero, with a one-sample $t$-test with a Bonferroni correction ( $p$ -

283 values were corrected for six $t$-tests). However, no significant differences were found,

284 while negative stimuli in a downward condition showed a modest effect size (negative

285 stimuli in a downward condition, $t(27)=2.61, p=.090, d=0.49$ and in an upward

286 condition, $t(27)=1.45, p=.948, d=0.27$; neutral stimuli in an upward condition, $t(27)$

$287=1.79, p=.504, d=0.34$ and in a downward condition, $t(27)=-1.42, p=.996, d=$

2880.27 ; positive stimuli in an upward condition, $t(27)=-1.88, p=.426, d=0.35$ and in a

289 downward condition, $t(27)=-0.61, p=1.000, d=0.12$ ), suggesting that no change was

290 caused by manual action on the emotional valence perception of the stimuli.

The correlation between the CES-D score and the changes in valence rating was

292 also tested. No significant correlation was found, however. Specifically, for negative

293 stimuli in an upward condition we found $r(26)=-.080, p=.686$; for a downward

294 condition, $r(26)=.231, p=.237$; for neutral stimuli in an upward condition, $r(26)$

$295=.195, p=.320$ and in a downward condition, $r(26)=-.273, p=.160$; for positive

296 stimuli in an upward condition, $r(26)=-.234, p=.160$ and in a downward condition, 
$297 \quad r(26)=.241, p=.216$.

\section{Experiment 2}

\section{1. Methods}

3. 1. 1. Participants. A total of 28 university students (mean age $=19.57, S D=$

$3041.45 ; 17$ females - none of whom participated in Experiment 1) from the classes of an

305 introductory psychology course at the University of Tokyo participated in this segment

306 of the study. The sample size was determined in the same way as Experiment 1. In

307 accordance with the Flinders Handedness Survey (Okubo et al., 2014), three

308 participants were found to be mixed-handed, but their data were included in the present

309 analyses for the same reason as Experiment 1. The others were right-handed. The

310 average score of all participants was $8.48(S D=3.91)$. The participants also completed the CES-D (Radloff, 1977), because depression can affect attentional bias to emotional 
312 stimuli (Peckham, McHugh, \& Otto, 2010). The CES-D score of the present participants

$313(M=11.39, S D=7.00)$ was comparable to healthy Japanese community dwellers

314 (Takano et al., 2017) as the difference between these samples was relatively small $(d=$

315 0.31). All participants had normal or corrected-to-normal visual acuity.

$318 \quad 1$ were used.

321 manipulation was introduced (Figure 3; MacLeod, Mathews, \& Tata, 1986). The first

322 fixation phase, action phase, and the second action phase were identical to those of the

323 rating task in Experiment 1. After the second fixation phase, the cue presentation phase

324 started with a pair of words appearing to the left and right of the fixation cross for 1,000

$325 \mathrm{~ms}$. These words were approximately $3.0^{\circ}$ from the center of the fixation cross

326 (measured from the center of the words). The word pairs were always composed of an 
327 emotional word (negative or positive) and a neutral word, written in two-lettered kanji,

328 subtending approximately $2.0^{\circ}$ in width and $1.0^{\circ}$ in height. Immediately after the word

329 pair disappeared, a white square target $\left(0.6^{\circ} \times 0.6^{\circ}\right)$ was presented at the location where

330 the word had been present. The participants were required to report the location of the

331 target (left or right) by pressing a key ("1" key on the numeric keypad for "left" and "3"

332 for "right") within 1,000 ms. When a response was given or 1,000 ms had passed

333 without a response, the trial was considered an error trial and the next trial was

334 immediately started.

335

In the modified dot-probe task, there were congruent trials and incongruent

336 trials; the target appeared in the same place as the emotional words during the congruent

337 trials, but in the opposite spot during the incongruent trials. As both negative and

338 positive words were used as emotional words, there were four types of trials: congruent-

339 negative, incongruent-negative, congruent-positive, and incongruent-positive trials.

340 Participants completed a block of practice, followed by two experimental blocks. In

341 each experimental block, there were eight trials each for combinations of action 
342 orientations (upward and downward) and trial types (congruent-negative, incongruent-

343 negative, congruent-positive, and incongruent-positive), resulting in 64 trials in total.

344 The trial order was randomized within participants. A break was provided between

$345 \quad$ blocks.

346 As in the rating task, there were vertical and horizontal sessions. The number of

347 trials and block design was the same as in the vertical session. The order of the sessions

$348 \quad$ was counterbalanced across participants.

[insert Figure 3. here] extremely short or long RTs (mean $\pm 2 S D)$ were excluded $(1.7 \%$ of the total). We averaged

352 the RTs of the trials for each condition and participant, then calculated changes in 353 attentional bias to examine whether attention to emotional stimuli was changed by upward 354 or downward movement. Then, we calculated the bias index (Koster, Crombez, 355 Verschuere, \& De Houwer, 2004; Mogg et al., 2000). The negative bias index was 356 calculated by subtracting the congruent-negative trial RTs from the incongruent RTs for 
357 each upward, downward, left, and right condition. Similarly, the positive bias index was

358 also calculated. We found that there was no significant difference between the negative

359 and positive bias indices between the left and right conditions: $p$-values Bonferroni-

360 corrected for two $t$-tests; negative bias index, $t(27)=-0.39, p=1.000, d=0.11$; positive

361 bias index, $t(27)=0.51, p=1.000, d=0.16$. Thus, the average of the bias indices for the

362 left and right conditions was used as the bias index for the horizontal condition. A two-

363 way repeated measure ANOVA was conducted on the bias index. Then, as in Experiment

364 1, we conducted $t$-tests with a Bonferroni correction for the main purpose of examining

365 whether upward and downward manual action changed attention to emotional stimuli

366 following the procedure of Kato et al. (2018). Finally, a correlation analysis was

367 conducted to examine the effect of depressive symptoms on the change of valence ratings.

The changes in the bias indices due to vertical action were calculated by

369 subtracting the bias index for the horizontal condition from that of the upward and

370 downward conditions (Sasaki et al., 2015; Kato et al., 2018). For example, the change in 
372 subtracting the positive bias index in the horizontal condition from the positive bias

373 index for the upward condition. Accordingly, the changes in the bias index for the

374 negative and positive stimuli in the upward and downward conditions were calculated.

\section{$375 \quad$ 3. 2. Results}

A repeated measures ANOVA with valence (negative, positive) and orientation

377 (upward, downward, horizontal) as within-participants factors was performed on the

378 change in bias index. The main effects of valence $\left(F(1,27)=0.04, p=.835, \eta_{p}^{2}=.002\right)$

379 and orientation $\left(F(2,54)=2.98, p=.061, \eta_{p}^{2}=.099\right)$ were not significant. The

380 interaction between valence and orientation was also not significant (Greenhouse-

381 Geisser corrected, $\left.F(1.53,41.18)=1.13, p=.318, \eta_{p}^{2}=.040\right)$.

382 For the primary purpose of Experiment 2, we investigated whether vertical

383 action caused any changes in attentional bias by conducting a one-sample two-tailed $t$ -

384 test against zero of the changes in bias indices (Figure 4) with a Bonferroni correction

385 (corrected for four $t$-tests). The change in the bias index for negative stimuli in the

386 upward condition was significantly higher than zero $(t(27)=2.80, p=.036, d=0.53)$, 
387 which indicates that upward movement increased attention to negative stimuli. No other 388 changes were significantly different from zero (negative bias in downward condition, $389 t(27)=1.59, p=.496, d=0.30$; positive bias in the upward condition, $t(27)=0.68, p=$ $3901.000, d=0.13$; positive bias in the downward condition, $t(27)=0.62, p=1.000, d=$ $391 \quad 0.12 ; p$-values Bonferroni-corrected). The correlation between the CES-D score and the changes in bias index was also 393 tested; however, no significant correlation was found. Our results showed negative bias 394 in the upward condition $r(26)=-.098, p=.621$ and in the downward condition, $r(26)$ $395=.210, p=.284$; positive bias in the upward condition, $r(26)=-.057, p=.772$ and in the 396 downward condition, $r(26)=.096, p=.626$. This suggests that depressive symptoms 397 did not affect the changes in attentional bias caused by manual action. 
402 manual movements on ratings of the emotional valences of the stimuli and attention to

403 subsequently presented emotional stimuli. Experiment 1 showed no effect of manual

404 movements introduced before the stimuli presentation on emotional valence rating.

405 Experiment 2 showed that manual action before the stimuli presentation only influenced

406 attention to negative stimuli when upward action was introduced, while downward

407 action did not affect attention. The present study revealed that metaphor-inductive

408 manual action prospectively affects attention to emotional verbal stimuli, as this was the

409 main investigative focus. The effects of manual action, however, were found to be

410 incongruent with space-valence metaphors.

4. 1. Relationship between metaphor-inductive vertical action and emotional

$413 \quad$ attention

The results of Experiment 2, which showed that upward action promoted

415 attention to negative stimuli, demonstrated a connection between metaphor-inductive

416 manual action and attention. As discussed above, vertical manual action has been 
417 known to affect valence rating (Kato et al., 2018; Sasaki et al., 2015) or

418 autobiographical memory (Casasanto \& Dijkstra, 2010). It is assumed that the

419 metaphorical association between space and valence was activated by manual action,

420 leading to an increased occurrence of metaphor-congruent information processing in

421 these studies. As Experiment 1 did not show any effects of the action on the emotional

422 ratings of the stimuli, perceptions of the emotional valence of the stimuli were not

423 affected prospectively by manual actions. Thus, the metaphor-inductive manual action

424 prospectively affected only attention. However, the effect is independent of the change

425 in valence perception, which was only observed when action is introduced after the

426 stimuli presentation (Kato et al., 2018; Sasaki et al., 2015).

Then, how did action cause the change in selective attention to emotional

428 stimuli? For a possible explanation, it has been reported that mood or motivational state

429 can affect attentional bias (Mogg \& Bradley, 1998). The change in attention was

430 possibly caused by changes in mood or motivational state evoked by metaphor-

431 inductive action. Action changes a mood or motivational state, according to previous 
432 studies on embodied cognition (Niedenthal, 2007; but see Wagenmakers et al., 2016, for

433 a controversy), although it is unclear as to whether a minimal action (like joystick

434 manipulation) is enough to change the internal mood state. Additionally, it is also

435 possible that the attentional bias changed without any change in the internal mood state.

436 The metaphorical effect of action, which is assumed to be caused by the activation of a

437 metaphorical association between valence and space, may not necessarily co-occur with

438 a change in internal mood state, as seen in a priming effect (Silvia, Phillips,

439 Baumgaertner, \& Maschauer, 2006; Soldat \& Sinclair, 2001). Nevertheless, it would be

440 interesting to compare the mood between before and after a task to examine the total

441 effect of the task on the mood state of participants.

\section{2. Metaphor incongruent effect of vertical action}

In some ways, the present results were not congruent with previous results. The

445 largest incongruence with the previous studies was the finding that upward movement

446 promoted attention to negative stimuli but not to positive stimuli, which does not match 
447 the "good is up" metaphor. The present study employed different methods from those in

448 other studies, and there was no previous report of metaphor-incongruent effect resulting

449 from metaphor-inductive action. However, a previous study reported that negatively

450 valenced words were recalled better when they were placed at the upper space of the

451 screen (Crawford, Cohn, \& Kim, 2014); this kind of incongruency is possibly observed

452 in the space-valence metaphor (while Crawford et al. (2014) themselves did not find a

$453 \quad$ significant effect of manual action).

We may be able to explain this metaphor-incongruent effect according to another

455 line of research; for example, the mood-incongruent effect. Previous studies have found

456 that people sometimes seek information with emotional valence that is different from

457 their mood state (Forgas, 1995), although people normally process mood-congruent

458 information better (Bower, 1981). This effect is called the mood-incongruent effect. The

459 mood-incongruent effect arises to moderate ones' internal mood state. It is assumed that

460 mood-incongruent information is sought when we are motivated to moderate the current

461 mood state or when some time has passed from the arising of a mood (Forgas \& 
462 Ciarrochi, 2002). Though these conditions do not seem to apply to the present

463 experimental setting, incongruent information processing evoked by the valence-space

464 metaphor may occur within some different conditions.

465 Joystick manipulation might have otherwise stimulated the unexpected effect of

466 embodied cognition, which disturbed the effect of the space-valence metaphor.

467 Cacioppo, Priester, and Berntson (1993) observed that arm flexion stimulated a positive

468 evaluation of presented stimuli, while arm extension stimulated a negative evaluation.

469 Cacioppo et al. (1993) assumed that arm flexion is related to approaching behavior (e.g.,

470 pulling an object), while the extension is related to avoidant behavior (e.g., pushing an

471 object away). In the present experiment, upward manual action included arm extension,

472 which may lead to negatively biased information processing. It should be noted that the

473 participants were required to return the joystick to its default position after every trial in

474 the action phase, which means that the participants always had to make downward

475 manual actions after an upward action, to return the joystick to the default position, and

476 vice versa. In other words, both arm extension and flexion were present in every trial in 
477 the vertical session. Thus, the mere physical movement does not seem to explain the

478 present results, as reported by Casasanto and Dijkstra (2010). According to Eder and

479 Rothermund (2008), if participants labeled their movement as "pushing joystick away,"

480 negative information processing may be promoted, even when the joystick and cursor

481 were moved upward. Referring to Casasanto and Dijkstra and Sasaki et al. (2015), we

482 did not instruct participants to "move cursor upward/downward," but instead instructed

483 them to "move the cursor to the red/blue bar" to observe the effect of vertical manual

484 action without semantically labeling the vertical space. Nevertheless, it is possible that

485 the participants voluntarily labeled their actions, which requires a somewhat different

486 motor action from that in the marble lifting (Casasanto \& Dijkstra, 2010) and touch

487 panel manipulation (Sasaki et al., 2015) used in previous studies. Overall, we cannot

488 specify the mechanism underlying the present results as there are few previous shreds of

489 evidence on the relationship between action and attention. It is hoped that future studies

490 will systematically investigate the relationship between the present results and previous

491 studies, like Casasanto and Dijkstra or Sasaki et al., to further enhance our 
492 understanding. More specifically, the effect of arm flexion and contraction can be

493 examined if the joystick returned to the default position automatically after the

494 participants moved the cursor and released the joystick in the future experiment.

495 Another incongruency with previous studies was that action only increased

496 attention to negative stimuli and had no apparent effect on attention to positive stimuli.

497 However, this result is not surprising, as previous studies suggest that a metaphorical

498 association between negative valence and lower position is stronger than the association

499 between positive valence and an upper position (Crawford \& Cacioppo, 2002; Meier \&

500 Robinson, 2006). Particularly, Meier and Robinson (2006) reported only the "bad is

501 down" effect in visual selective attention. Thus, the negativity bias in the space-valence

502 metaphor may be considered as one cause of the absence of the action effect on

503 attention to positive stimuli. Additionally, in a line of previous attentional bias studies, it

504 is often reported that attentional bias to positive stimuli is rarely observed, as compared

505 to an attentional bias to negative stimuli (Fox, Russo, \& Dutton, 2002). Detecting

506 negative information is more biologically and evolutionally important for survival than 
507 positive information (Crawford \& Cacioppo, 2002; Shweder, Haidt, Horton, \& Joseph,

508 2008; Tovote, Fadok, \& Lüthi, 2015). Thus, attentional bias to negative stimuli is often

509 more prominent than attentional bias to positive stimuli.

510

$511 \quad$ 4. 3. Limitations

There were some limitations in the present methods. The first limitation is that

513 the present study could not examine the time course of the metaphorical effects of an

514 action. In the present study, the action was always inserted one second before the

515 presentation of emotional stimuli. As Kato et al. (2018) and Sasaki et al. (2015) found,

516 not only the order of action and stimuli presentation, but also the temporal proximity

517 between action and stimuli, can affect emotional information processing. An action may

518 also be introduced during the stimuli presentation, as reported by Casasanto and Djkstra

519 (2010). A time-course effect on metaphor-inductive action should be systematically

$520 \quad$ investigated in future studies.

521 Second, the apparatus in the present study might not have been optimized. We 
522 referred to previous studies (Kato et al., 2018; Sasaki et al., 2016) to develop the present

523 experimental settings. However, it is unclear whether the amount or intensity of action

524 was appropriate. For example, there was asymmetry in the difficulty of the upward and

525 downward manipulations in the present study due to gravity. This may have caused a

526 somewhat negative nuance or influence on upward manual action. Thus, future studies

527 should carefully investigate the potential effects of various motor properties (e.g., loads,

528 speeds, and directions) on emotional and metaphorical processing.

Additionally, the present study used a dot-probe task, which is a task to measure

530 visual selective attention. There are many other kinds of visual attention tasks as well.

531 For example, Posner's cueing paradigm (Posner, 1980) can measure attentional

532 engagement and disengagement separately. Visual search paradigms, or the monitoring

533 of eye-gaze, are also useful ways to measure attentional bias. Moreover, the present

534 results are limited to visual attention. However, the metaphorical effect is possibly

535 observed in auditory attention, as attention to verbal stimuli was affected by metaphor-

536 inductive action. In these ways, the effect of the space-valence metaphor in various 
$537 \quad$ aspects of attention can be investigated in future studies.

\section{4. Conclusions}

The present study investigated the effects of motor action introduced before the

541 emotional stimuli presentation and space-valence metaphors on the valence rating of

542 emotional stimuli and attention to emotional information. The results showed that

543 valence rating was not affected, while selective attention to emotional words was

544 affected by manual action. However, only the upward action increased attention to

545 negative stimuli, which was not congruent with space-valence metaphors. It is hoped

546 that the effects of the experimental setting, including the time course effects of the

547 action and stimuli presentation, on attention will be investigated in detail in future

$548 \quad$ studies. Future studies should examine the effect of metaphor-inductive action on

549 emotional processing and expand these findings into the field of prospective memory. In

550 the present study, it was suggested that vertical manual action prospectively affects

551 attention to emotional stimuli; however, the effect was metaphor-incongruent. On the 
552 other hand, the previous studies have shown that manual action retrospectively affects

553 emotional information processing in a metaphor-congruent manner (Kato et al., 2018;

554 Sasaki et al., 2015). Taken together, the prospective effect of metaphor-inductive action

555 can be inverted from a retrospective one, and we can expect that the metaphor-

556 incongruent effect of action will affect prospective memory (or, there may be no effect

557 as Kato et al. showed). In this way, future research can expand present findings into

558 other fields of cognitive psychology.

These experiments suggested that attentional change by manual action may be

560 independent of change in valence perception. Previous studies have discussed the

561 association between action and attention (e.g., Smith \& Schenk, 2012), and additionally,

562 the present study suggested that spatial metaphor may be associated with this

563 relationship. If the knowledge on the relationship between metaphor-inductive action

564 and attention is accumulated in the future, it can be practically applied to various fields.

565 For example, the present results suggest that if we want people to attend negative

566 information (e.g., precautionary statements), we can introduce upward action before the 
567 presentation of them (e.g., people have to raise a lever to get tickets for a vending

568 machine). We can apply the present findings to work in clinical psychology, as

569 metaphor-inductive motor action may help patients with depression or anxiety to

570 overlook or ignore negative information. For example, inhibition of vertical manual

571 action (especially upward action) can decrease attention to negative stimuli. Future

572 research should explore such practical applications of metaphor-inductive action. 


\section{References}

$574 \quad$ Bower, G. H. (1981). Mood and memory. American Psychologist, 36(2), 129-148. https://doi.org/10.1037/0003-066X.36.2.129

576 Cacioppo, J. T., Priester, J. R., \& Berntson, G. G. (1993). Rudimentary Determinants of Attitudes. II: Arm Flexion and Extension Have Differential Effects on Attitudes. Journal of Personality and Social Psychology. 65(1), 5-17. https://doi.org/10.1037/0022-3514.65.1.5

Casasanto, D. (2009). Embodiment of abstract concepts: Good and bad in right-and lefthanders. Journal of Experimental Psychology: General, 138(3), 351-367.

Casasanto, D., \& Dijkstra, K. (2010). Motor action and emotional memory. Cognition, 115(1), 179-185. https://doi.org/10.1016/J.COGNITION.2009.11.002

584 Crawford, L. E., \& Cacioppo, J. T. (2002). Learning Where to Look for Danger: 
587 Crawford, L. E., Cohn, S. M., \& Kim, A. B. (2014). " Good Is Up" Is Not Always

588 Better: A Memory Advantage for Words in Metaphor-Incompatible Locations.

$589 \quad$ PloS one, 9(9), e108269.

590 Crawford, L. E., Margolies, S. M., Drake, J. T., \& Murphy, M. E. (2006). Affect biases memory of location: Evidence for the spatial representation of affect. Cognition \& Emotion, 20(8), 1153-1169. https://doi.org/10.1080/02699930500347794

593 Eder, A. B., \& Rothermund, K. (2008). When Do Motor Behaviors (Mis)Match Affective Stimuli? An Evaluative Coding View of Approach and Avoidance Reactions. Journal of Experimental Psychology: General. 137(2), 262-281. https://doi.org/10.1037/0096-3445.137.2.262

Faul, F., Erdfelder, E., Buchner, A., \& Lang, A.-G. (2009). Statistical power analyses using G*Power 3.1: Tests for correlation and regression analyses. Behavior 
600 Fetterman, A. K., Wilkowski, B. M., \& Robinson, M. D. (2018). On Feeling Warm and Being Warm. Social Psychological and Personality Science, 9(5), 560-567. https://doi.org/10.1177/1948550617712032

603 Forgas, J. (1995). Mood and judgement: The affect infusion model (AIM). Psychological Bulletin. 117(1). 39-66.

Forgas, J. P., \& Ciarrochi, J. V. (2002). On managing moods: Evidence for the role of homeostatic cognitive strategies in affect regulation. Personality and Social Psychology Bulletin, 28(3), 336-345.

608 Fox, E., Russo, R., \& Dutton, K. (2002). Attentional bias for threat: Evidence for delayed disengagement from emotional faces. Cognition and Emotion. 16(3), 355379. https://doi.org/10.1080/02699930143000527

611 Förster, J., \& Strack, F. (1997). Motor Actions in Retrieval of Valenced Information: A Motor Congruence Effect. Perceptual and Motor Skills, 85(3_suppl), 1419-1427. 
614 Förster, J., \& Strack, F. (1998). Motor Actions in Retrieval of Valenced Information: II. Boundary Conditions for Motor Congruence Effects. Perceptual and Motor Skills, 86(3_suppl), 1423-1426. https://doi.org/10.2466/pms.1998.86.3c.1423

617 Gherri, E., \& Eimer, M. (2010). Manual response preparation disrupts spatial attention: An electrophysiological investigation of links between action and attention. Neuropsychologia, 48(4), 961-969. http://doi.org/10.1016/j.neuropsychologia.2009.11.017

621 Humphreys, G. R., \& Buehner, M. J. (2009). Magnitude estimation reveals temporal binding at super-second intervals. Journal of Experimental Psychology: Human Perception and Performance, 35(5), 1542-1549. https://doi.org/10.1037/a0014492

624 Kato, T., Imaizumi, S., \& Tanno, Y. (2018). Metaphorical Action Retrospectively but https://doi.org/10.3389/fpsyg.2018.01927

627 Kohler, C. G., Hoffman, L. J., Eastman, L. B., Healey, K., \& Moberg, P. J. (2011). 
review. Psychiatry Research, 188(3), 303-309.

630

http://doi.org/10.1016/J.PSYCHRES.2011.04.019

631 Koster, E. H. W., Crombez, G., Verschuere, B., \& De Houwer, J. (2004). Selective attention to threat in the dot probe paradigm: Differentiating vigilance and https://doi.org/10.1016/J.BRAT.2003.08.001

635 Lakoff, G., \& Johnson, M. (1999). Philosophy in the flesh. New York: Cambridge

636 University Press

637 Lakoff, G., \& Johnson, M. (1980). The Metaphorical Structure of the Human Conceptual System. Cognitive Science, 4(2), 195-208.

639 https://doi.org/10.1207/s15516709cog0402_4

640 Lynott, D., \& Coventry, K. (2014). On the ups and downs of emotion: Testing between conceptual-metaphor and polarity accounts of emotional valence-spatial location interactions. Psychonomic Bulletin \& Review, 21(1), 218-226. 
644 MacLeod, C., Mathews, A., \& Tata, P. (1986). Attentional bias in emotional disorders. Journal of Abnormal Psychology, 95(1), 15-20. https://doi.org/10.1037/0021$\underline{843 X .95 .1 .15}$

647 Matsumoto, K. (2006). Relation between the emotional Stroop task and the probe detection task. Socio-Environmental Studies, 11, 203-216.

649 Maxwell, J. S., \& Davidson, R. J. (2007). Emotion as Motion. Psychological Science, 650 18(12), 1113-1119. https://doi.org/10.1111/j.1467-9280.2007.02033.x

651 Meier, B. P., \& Robinson, M. D. (2004). Why the Sunny Side Is Up: Associations Between Affect and Vertical Position. Psychological Science, 15(4), 243-247.

653 https://doi.org/10.1111/j.0956-7976.2004.00659.x

654 Meier, B. P., Hauser, D. J., Robinson, M. D., Friesen, C. K., \& Schjeldahl, K. (2007). What's "up" with God? Vertical space as a representation of the divine. Journal of 656 Personality and Social Psychology, 93(5), 699-710. https://doi.org/10.1037/0022- 
658 Meier, B. P., \& Robinson, M. D. (2006). Does “feeling down” mean seeing down?

659 Depressive symptoms and vertical selective attention. Journal of Research in 660 Personality, 40(4), 451-461. https://doi.org/10.1016/J.JRP.2005.03.001

661 Mogg, K., \& Bradley, B. P. (1998). A cognitive-motivational analysis of anxiety. Behaviour Research and Therapy, 36(9), 809-848. Retrieved from

663 http://www.sciencedirect.com/science/article/pii/s0005-7967(98)00063-1

664 Mogg, K., McNamara, J., Powys, M., Rawlinson, H., Seiffer, A., \& Bradley, B. P. 665 (2000). Selective attention to threat: A test of two cognitive models of anxiety. Cognition \& Emotion, 14(3), 375-399. https://doi.org/10.1080/026999300378888

667 Nicholls, M. E. R., Thomas, N. A., Loetscher, T., \& Grimshaw, G. M. (2013). The 668 Flinders Handedness survey (FLANDERS): A brief measure of skilled hand preference. Cortex, 49(10), 2914-2926. https://doi.org/10.1016/J.CORTEX.2013.02.002

671 Niedenthal, P. M. (2007). Embodying Emotion. Science, 316(5827), 1002-1005. https://doi.org/10.1126/science.1136930 
673 Nishiguchi, Y., Takano, K., \& Tanno, Y. (2015). Explicitly guided attentional bias modification promotes attentional disengagement from negative stimuli. Emotion, 15(6), 731-741. https://doi.org/10.1037/a0039117

676 Okubo, M., Suzuki, H., \& Nicholls, M. E. R. (2014). (A Japanese version of the FLANDERS handedness questionnaire). Shinrigaku Kenkyu: The Japanese Journal of Psychology, 85(5), 474-481. https://doi.org/10.4992/JJPSY.85.13235

679 Oosterwijk, S., Rotteveel, M., Fischer, A. H., \& Hess, U. (2009). Embodied emotion concepts: How generating words about pride and disappointment influences posture. European Journal of Social Psychology, 39(3), 457-466. https://doi.org/10.1002/ejsp.584

683 Peckham, A. D., McHugh, R. K., \& Otto, M. W. (2010). A meta-analysis of the magnitude of biased attention in depression. Depression and Anxiety, 27(12), 1135-42. http://doi.org/10.1002/da.20755

686 Posner, M. I. (1980). Orienting of attention. The Quarterly Journal of Experimental Psychology, 32(1), 3-25. http://doi.org/10.1080/00335558008248231 
688 Radloff, L. S. (1977). The CES-D Scale: A Self-Report Depression Scale for Research in the General Population. Applied Psychological Measurement, 1(3), 385-401. http://doi.org/10.1177/014662167700100306

691 Riskind, J. H., \& Gotay, C. C. (1982). Physical posture: Could it have regulatory or feedback effects on motivation and emotion? Motivation and Emotion, 6(3), 273298. https://doi.org/10.1007/BF00992249

694 Sasaki, K., Yamada, Y., \& Miura, K. (2015). Post-determined emotion: motor action retrospectively modulates emotional valence of visual images. Proceedings. Biological Sciences, 282(1805), 20140690. https://doi.org/10.1098/rspb.2014.0690

697 Sasaki, K., Yamada, Y., \& Miura, K. (2016). Emotion biases voluntary vertical action only with visible cues. Acta Psychologica, 163, 97-106. https://doi.org/10.1016/j.actpsy.2015.11.003 Depression. Seishin Igaku. Clinical Psychiatry, 27(6), 717-723. 
Shweder, R. A., Haidt, J., Horton, R., \& Joseph, C. (2008). The cultural psychology of the emotions: Ancient and renewed. In M. Lewis, J. M. Haviland-Jones, \& L. F. Barrett (Eds.), Handbook of Emotions (pp. 409-427). New York, NY, US: Guilford Press.

Silvia, P. J., Phillips, A. G., Baumgaertner, M. K., \& Maschauer, E. L. (2006). Emotion concepts and self-focused attention: Exploring parallel effects of emotional states and emotional knowledge. Motivation and Emotion, 30(3), 225-231.

Smith, D. T., \& Schenk, T. (2012). The premotor theory of attention: time to move on? Neuropsychologia, 50(6), 1104-1114.

Soldat, A. S., \& Sinclair, R. C. (2001). Colors, Smiles, and Frowns: External Affective Cues Can Directly Affect Responses to Persuasive Communications in a Moodlike Manner Without Affecting Mood. Social Cognition, 19(4), 469-490. https://doi.org/10.1521/soco.19.4.469.20756 
properties of the written version of the autobiographical memory test in a japanese community sample. Psychiatry Research, 248, 56-63. http://doi.org/10.1016/j.psychres.2016.12.019

Tovote, P., Fadok, J. P., \& Lüthi, A. (2015). Neuronal circuits for fear and anxiety. Nature Reviews Neuroscience, 16(6), 317-331. https://doi.org/10.1038/nrn3945

723 Wagenmakers, E. J., Beek, T., Dijkhoff, L., Gronau, Q. F., Acosta, A., Adams Jr, R. stepper (1988). Perspectives on Psychological Science, 11(6), 917-928.

726 Wapner, S., Werner, H., \& Krus, D. M. (1957). The Effect of Success and Failure on https://doi.org/10.1111/j.1467-6494.1957.tb01563.x

729 Zhang, X., Li, Q., \& Zuo, B. (2014). Gaze direction and brightness can affect selfreported emotion. Journal of Environmental Psychology, 40, 9-13. https://doi.org/10.1016/J.JENVP.2014.04.004 


\section{Figure Captions}

734 Figure 1. (A) Schematic procedure of the rating task in Experiment 1. (B) Schematic $735 \quad$ illustration of the present experiment setting.

736 Figure 2. Changes in valence ratings for negative, neutral, and positive stimuli caused 737 by vertical manual action in comparison to horizontal action in Experiment 1. Error bars 738 represent the standard error of the mean.

739 Figure 3. Schematic procedure of the modified dot-probe task in Experiment 2.

$740 \quad$ Figure 4. Changes in bias index for negative and positive stimuli caused by vertical

741 manual action in comparison to horizontal action in Experiment 2. Asterisk represents a 742 significant difference between the change in bias index and zero ( $* p<.05$, two-tailed, 743 Bonferroni-corrected). Error bars represent the standard error of the mean. 
746 Japanese words used in Experiments 1 and 2. English translations in parentheses.

\begin{tabular}{|c|c|c|c|}
\hline Practice & Negative & Neutral & Positive \\
\hline 角度 (angle) & 混雑 (crowded) & 任期（tenure） & $\begin{array}{l}\text { 優勝 (win the } \\
\text { championship) }\end{array}$ \\
\hline \multirow{15}{*}{$\begin{array}{l}\text { 石油 } \\
\text { (petroleum) }\end{array}$} & 迷惑 (nuisance) & 吞気 (carefree) & 陽気 (merry) \\
\hline & 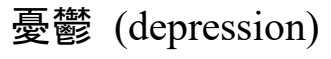 & 部品（parts） & 裕福 (wealthy) \\
\hline & 後悔 (regret) & 印象 (impression) & 親友 (close friend) \\
\hline & 死亡 (death) & 勝敗 (results) & 誠実 (sincere) \\
\hline & 拒絶 (refusal) & 逆算 (inversion) & 敬愛 (adoration) \\
\hline & $\begin{array}{l}\text { 無力 } \\
\text { (helplessness) }\end{array}$ & 座席 (seat) & 感銘 (deeply impressed) \\
\hline & 中毒 (addiction) & 染料 (dye) & 爽快（exhilarating） \\
\hline & $\begin{array}{l}\text { 全滅 } \\
\text { (annihilation) }\end{array}$ & 体調 (condition) & 勝利（victory） \\
\hline & 気絶 (faint) & 脈拍 (pulsation) & 安心 (relief) \\
\hline & 敗者 (loser) & $\begin{array}{l}\text { 朗読 (reading } \\
\text { aloud) }\end{array}$ & 信頼（trust） \\
\hline & 敵意 (hostility) & 浴槽 (bathtub) & 大吉 (great fortune) \\
\hline & 危害 (harm) & 呼吸 (breath) & 優良 (excellent) \\
\hline & 苦手 (dislike) & 近況 (recent state) & 安全 (safety) \\
\hline & 卑劣 (mean) & 発言 (remark) & 好感 (likable) \\
\hline & 陰気 (gloomy) & 上司 (boss) & 善意 (goodwill) \\
\hline
\end{tabular}

